\title{
Efficiency of manual resuscitators at birth
}

\author{
D FIELD, A D MILNER, AND I E HOPKIN
}

Department of Neonatal Medicine and Surgery, City Hospital, Nottingham

SUMmARY The effectiveness of five neonatal/ paediatric manual resuscitators was assessed in a group of babies born by caesarean section. Results showed that devices incorporating a large volume reservoir produced the greatest tidal volume, while those with smaller volume reservoirs could not be considered satisfactory for routine use during neonatal resuscitation.

The use of bag and mask resuscitation has been a routine feature of neonatal care for some years. ${ }^{1}$ Initially, this form of respiratory support was the keystone of resuscitation at birth and was also employed by some to cope with longer term ventilation. ${ }^{2}$ Currently, many larger centres prefer to use endotracheal intubation as the method of choice for resuscitation at birth, reserving bag and mask systems for situations in which medical personnel trained in endotracheal intubation are not routinely available. In many smaller delivery units the use of bag and mask resuscitation remains of primary importance. Similarly, community midwives rely on this technique when attending domiciliary deliveries.

From our previous experience we had noted manual resuscitators to be less effective than endotracheal intubation in producing satisfactory lung inflation. ${ }^{3}$ We therefore gave consideration to the factors that could alter the effectiveness of any particular bag and mask system. These were the leak around the mask, the peak pressure produced by the system (limited by the basic valve arrangement of the device), and the duration that the inflation pressure could be maintained. The evidence for this last point relates to our work on the normal first breath, where we found that a sustained inspiratory effort was more effective in producing a gaseous functional residual capacity than similar pressure swings of a more transitory nature. ${ }^{4}$

A recent report has highlighted the importance of the face mask itself during resuscitation and shown the overall advantage of using a 'round' mask compared with the Rendall Baker type of device. ${ }^{5}$

Our aim was to assess how the variation in peak pressure produced by different bags and differences in the extent to which this pressure could be maintained altered the resulting tidal exchange.

\section{Apparatus}

A system was employed that enabled changes in $\overrightarrow{0}$ both flow and pressure to be recorded during resuscitation.

Flow was measured by Mercury disposable $\frac{\rho}{\Omega}$ pneumotachograph. Using appropriate adapters it $\stackrel{0}{\varnothing}$ was possible to connect this device between the patient manifold and the mask for each device under $\vec{\omega}$ test. The pneumotachograph was connected by tubes of equal length to an SE Laboratories dif- $\triangle$ ferential pressure transducer and the signal recorded on to a Devices chart recorder. To derive changes in tidal volume from this data the expiratory flow $\bar{z}$ signal was integrated using a digitiser and Commodore 4032 computer with a commercial programme. $\frac{\Gamma}{\square}$ A calibration factor was obtained by injecting and $\overrightarrow{0}$ withdrawing known volumes of air. The expiratory portion of the trace was chosen as any leak around the face mask during expiration should have been minimal. The $63 \%$ rise time for the pneumotachograph/differential pressure transducer and tubes was 6 milliseconds.

Changes in pressure were monitored using a Bell $\stackrel{\mathbb{D}}{2}$ and Howell pressure transducer. This was connected $\overrightarrow{\overrightarrow{0}}$ into the face mask using wide bore tubing. Calibration was performed using a water manometer. The $63 \%$ rise time was satisfactory at $6 \mathrm{msec}$. To eliminate differences in performance resulting from variations in the masks used all bags were fitted to an Ambu round face mask. We have found the $\frac{5}{3}$ round type of face mask to produce the most satisfactory seal, and a recent report has confirmed this impression. ${ }^{5}$

\section{Method and subjects}

We assessed five bags:

(1) neonatal Laerdal resuscitator (volume $240 \mathrm{ml}$ );

(2) paediatric Laerdal resuscitator $(500 \mathrm{ml})$;

(3) Penlon infant resuscitator $(275 \mathrm{ml})$;

(4) Ambu baby resuscitator $(450 \mathrm{ml})$;

(5) Samson neonatal resuscitator $(200 \mathrm{ml})$.

Our intention was to collect data on pressure and 70 volume achieved during 10 resuscitations by each $\stackrel{\overrightarrow{0}}{0}$ system. All babies included in the study were born $\stackrel{\odot}{\circ}$ by caesarean section. We chose this group of infants $\stackrel{\mathbb{Q}}{\mathscr{Q}}$ 
as after delivery by caesarean section a period of secondary apnoea is often observed, during which the baby is temporarily apnoeic and requires respiratory support or stimulation. It was during these periods that many of our measurements were made. At the time of the study all babies had an Apgar score of 6 or less with 0 for respiratory effort.

We gained full data on 45 resuscitations, having attended roughly double that number of deliveries. Mean birth weight of the subjects was $3240 \mathrm{~g}$ (range $2100-4100 \mathrm{~g}$ ), and mean gestation was 39.4 weeks (range 35-41 weeks).

After delivery in those babies where it was apparent some form of resuscitation was required the upper airway was cleared with a mucous extractor and the face mask placed over the nose and mouth so as to produce the optimal seal. Inflation then took place. The intention was to produce sustained inflations at a high pressure while leaving the blow off valves for each bag operational.

Analysis of data. All traces were examined for evidence of spontaneous respiratory effort, and if this was present in any of the first five inflations after placement of the mask the study was excluded. For each resuscitation we analysed mean pressure and expired volume over the first three inflations. In most of the studies we recorded well in excess of 10 inflations before spontaneous respiratory efforts were observed.

\section{Results}

Full data on 10 resuscitations were obtained for all devices except the Samson (Table). Also included is a group mean value for three times dead space as an estimate of what might be considered a 'reasonable' tidal volume. Information for the Samson is limited to five studies, as although it was possible to obtain reasonable pressures and volumes with this bag it was also inconsistent. The concertina nature of the bag tended to produce rapid emptying if a leak of any magnitude was present and before adjustment could be made to improve the seal. This, combined with its tendency to separate during use, led us to limit the number of studies with this bag to five. Of the other bags both the neonatal Laerdal and the Penlon consistently failed to produce good volumes. The paediatric Laerdal and in particular the Ambu performed well and were consistently easy to use. Group means for all fell well short of the value for three times the dead space; the values obtained by the Ambu, however, approach those we have obtained previously during resuscitation with an endotracheal tube. ${ }^{6}$ In support of our belief that sustained inspiratory efforts at birth produce better gaseous expansion than more transitory pressure changes, we noted that it was with the larger volume resuscitators (Ambu and paediatric Laerdal) that the best volumes were produced and the longest inflation times were obtained.

\section{Discussion}

It would seem from our results that only the Ambu and paediatric Laerdal resuscitator bags could be considered as appropriate for routine use at delivery (the paediatric Laerdal of course is not marketed as a neonatal resuscitator). We feel the larger tidal volumes occur simply because with these two devices higher pressures can be obtained and sustained. The use of ever increasing volume bags, however, does not produce a linear response in tidal volume. We carried out six resuscitations with an adult Laerdal bag (internal volume $1600 \mathrm{ml}$ ) and found that the tidal volumes obtained were poor as the large size of this device made it cumbersome, and this prejudiced the seal around the face.

Table Data relating to the five types of resuscitator bags

\begin{tabular}{|c|c|c|c|c|c|}
\hline \multirow{2}{*}{$\begin{array}{l}\text { Type of } \\
\text { resuscitator } \\
\text { bag }\end{array}$} & \multirow{2}{*}{$\begin{array}{l}\text { No of } \\
\text { studies }\end{array}$} & \multicolumn{3}{|c|}{ Mean of first three inflations } & \multirow{2}{*}{$\begin{array}{l}\text { Three times } \\
\text { dead space } \\
\text { value* }\end{array}$} \\
\hline & & $\begin{array}{l}\text { Inflation } \\
\text { pressure }\end{array}$ & $\begin{array}{l}\text { Expiratory } \\
\text { volume }\end{array}$ & $\begin{array}{l}\text { Length of } \\
\text { inflation }\end{array}$ & \\
\hline Neonatal Laerdal & 10 & $20 \cdot 2$ & $5 \cdot 5$ & $1 \cdot 11$ & $22 \cdot 1$ \\
\hline Paediatric Laerdal & 10 & $26 \cdot 9$ & $10 \cdot 4$ & $1 \cdot 26$ & $22 \cdot 2$ \\
\hline Penlon infant & 10 & $19 \cdot 2$ & $8 \cdot 3$ & $0 \cdot 80$ & $17 \cdot 6$ \\
\hline Ambu baby & 10 & $30 \cdot 3$ & $15 \cdot 4$ & $1 \cdot 80$ & $21 \cdot 3$ \\
\hline
\end{tabular}

${ }^{*}$ Dead space $\bumpeq 2.2 \mathrm{ml} / \mathrm{kg}$.

Expired volume (Student $t$ test):

Ambu $v$ Laerdal paediatric not significant:

Ambu $v$ Penlon $\mathrm{p}<0 \cdot(\mathbf{0}(\mathbf{0 ) 1}$ :

Ambu $v$ Laerdal neonatal $p<0 \cdot(0)(0) 1$;

Laerdal pacdiatric $v$ Penlon $\mathrm{p}<0 \cdot(\mathbf{0}(0) 1$ :

Laerdal neonatal $v$ Penlon not significant:

Lacrdal paediatric $v$ Laerdal neonatal $\mathrm{p}<() \cdot(\mathbf{0}) 1$. 
It is our opinion that for bag and mask resuscitation at birth three facts are now clear:

(1) round and not Rendall Baker type masks should be used;

(2) reservoirs of sufficient volume should be available to sustain inflation pressure for at least one second, and that the 'blow off' pressure should be roughly $30 \mathrm{cms} \mathrm{H}_{2} \mathrm{O}$;

(3) regular training should be given to those intended to use them.

\section{References}

1 Hull D. Lung expansion and ventilation during resuscitation of asphyxiated newborn infants. $J$ Pediatr 1969;75:47-58.

2 Hesse $\mathrm{H}$ de V, Harrison VC, Klein M, Malan AS. Intermittent positive pressure ventilation in hyaline membrane disease. $J$ Pediatr 1970;76:183-93.

${ }^{3}$ Milner AD, Vyas H, Hopkin IE. Efficacy of facemask resuscitation at birth. $\mathrm{Br}$ Med J 1984;289:1563-5.

4 Milner AD, Saunders RA. Hopkin IE. Pressure and volume changes during the first breath of human neonates. Arch Dis Child 1977;52:918-24.

5 Palme C, Hystrom B, Tunell R. The evaluation of the efficacy of face masks in the resuscitation of newborn infants. Lancet $1985 ; \mathbf{i}: 207-10$.

- Milner AD, Boon AW, Hopkin IE. Lung expansion, tidal exchange and formation of the functional residual capacity during resuscitation of asphyxiated infants. $J$ Pediatr 1979;6:1031-6.

Correspondence to Dr D Field, Department of Child Health Leicester Royal Infirmary, Infirmary Square, Leicester LE1 5WW

Received 3 December 1985 